be prevented constitute a major problem in family care-giving. This study attempts to find out through the use of questionnaires and focus group interviews what young people know about elder abuse and some preventive mechanisms. Data were collected from 480 undergraduates. Result show that $80 \%$ of respondents have knowledge of what constitute elder abuse while $63 \%$ are aware of some preventive mechanism. Other findings show that apart from sex of the respondents other variables such as living with an older person, age and place of residence have no relationship with knowledge of elderly abuse or preventive mechanism. Some of the recommendations include that the study of social gerontology should be made a part of the school curriculum both at the lower and higher institution of learning in Nigeria so as to inculcate the values in the youths so as to curtail elder abuse in future.

\title{
0105 WHAT CONSTITUTE ELDER ABUSE: A STUDY OF KNOWLEDGE AND PREVENTIVE MECHANISM KNOWN TO YOUNG PEOPLE
}

U 0 Okoye*, R I Echezona Correspondence: Department of Social Work, Faculty of the Social Sciences, University of Nigeria, Nsukka, Enugu State 410002, Nigeria

\subsection{6/ip.2010.029215.105}

The population of the older people all over the world today is increasing steadily so also their needs. The near total dependence of the older people on their children and relations for care giving in places like Nigeria, most cases leave a broad window for elder abuse to occur even without the care giver being aware of it. It is generally believed that lack of knowledge about elder abuse and not knowing the mechanisms through which it can 